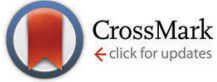

Cite this: Phys. Chem. Chem. Phys., $2015,17,6415$

Received 9th December 2014, Accepted 26th January 2015

DOI: $10.1039 / c 4 c p 05735 j$

www.rsc.org/pccp

\section{Rotation-induced recovery and bleaching in magnetic resonance}

\author{
Angel J. Perez Linde, ${ }^{\star a}$ Srinivas Chinthalapalli, ${ }^{a}$ Diego Carnevale ${ }^{a}$ and \\ Geoffrey Bodenhausen ${ }^{\text {abcd }}$
}

\begin{abstract}
Thurber and Tycko recently described a 'bleaching effect' that occurs in magnetic resonance when solid samples that are doped with paramagnetic agents are subjected to rotation by magic angle spinning (MAS) in a static magnetic field with a rotation period comparable to the longitudinal relaxation time $T_{1 \mathrm{e}}$ of the electron spins. The bleaching effect has been investigated by Thurber and Tycko in samples spinning at temperatures near $20 \mathrm{~K}$ in a field of $9.4 \mathrm{~T}$ and by Corzilius et al. near $80 \mathrm{~K}$ in a field of $4.9 \mathrm{~T}$. In our experience, the bleaching effect is not very severe at temperatures near $100 \mathrm{~K}$ in a field of $9.4 \mathrm{~T}$ at spinning frequencies up to $12 \mathrm{kHz}$. Bleaching can partly cancel DNP enhancements that are normally evaluated by comparing signal intensities with and without microwave irradiation. The signal attenuation due to doping and sample rotation is usually not taken into consideration when defining enhancement factors. In this paper, we describe a novel observation that the rotation of glassy samples doped with lanthanides spinning at frequencies as low as $0.1 \mathrm{kHz}$ can lead to a significant reduction of the spinlattice relaxation times $T_{1}\left({ }^{1} H\right)$ of protons. This effect, which bears similarities with the so-called spin refrigerators, may contribute to the success of 'brute force polarization' at sample temperatures in the $\mathrm{mK}$ range. The acceleration of longitudinal proton relaxation also allows one to improve the signal-tonoise ratio per unit time.
\end{abstract}

\section{Introduction}

Dynamic nuclear polarization (DNP) in solid samples relies on a transfer of polarization from electron spins to nuclear spins induced by irradiation of electron paramagnetic resonance (EPR) transitions. This allows one to boost the sensitivity of nuclear magnetic resonance (NMR). The effect was predicted by Overhauser $^{1}$ and confirmed by Carver and Slichter in $1953 .^{2}$ Depending on the number of electron and nuclear spins involved in this process, different DNP mechanisms may be effective. In a system comprising a single electron spin and a single nuclear spin, the mechanism is known as the 'solid effect'. ${ }^{3}$ In the presence of two electron spins and a single nuclear spin, a 'cross effect' may occur. ${ }^{4-6}$ For larger numbers of spins, a 'thermal mixing' process should be considered., ${ }^{3,7-9}$ Other methods can also produce large enhancements of nuclear polarizations, like optical pumping and proton spin refrigeration. ${ }^{10}$ DNP experienced a renaissance in the 90 's ${ }^{11,12}$

\footnotetext{
${ }^{a}$ Institut des Sciences et Ingénierie Chimiques (ISIC), Ecole Polytechnique Fédérale de Lausanne (EPFL), 1015 Lausanne, Switzerland. E-mail: ppxajp@gmail.com

${ }^{b}$ Ecole Normale Supérieure-PSL Research University, Département de Chimie, 24 rue Lhomond, 75005 Paris, France

${ }^{c}$ Sorbonne Universités, UPMC Univ. Paris 06, 4 place Jussieu, 75005, Paris, France

${ }^{d}$ CNRS UMR 7203 LBM, 75005, Paris, France
}

with the advent of gyrotrons combined with magic angle spinning (MAS), which can multiply the sensitivity by several orders of magnitude in glassy samples doped with paramagnetic agents. Renewed interest in low temperature DNP was triggered by the invention of dissolution DNP. ${ }^{13}$ This method also generated interest for 'brute force polarization' where the sample is cooled to $\mathrm{mK}$ temperatures to enhance the Zeeman polarization, without resorting to any microwave irradiation. ${ }^{14-16}$

Recently, a decrease of nuclear polarization due to the rotation of glassy samples doped with paramagnetic impurities has been observed ${ }^{17}$ and evaluated for various radicals at $4.9 \mathrm{~T}$ and $80 \mathrm{~K}$ (ref. 18) and at $9.4 \mathrm{~T}$ and $18 \mathrm{~K} .{ }^{19}$ This decrease tends to cancel some of the benefits of DNP. The enhancement factors have to be carefully measured to evaluate the balance between the positive and negative contributions to the nuclear polarization that can arise from doping with different paramagnetic agents such as nitroxides and lanthanides, microwave irradiation, sample spinning, low temperatures, and high magnetic fields.

We shall briefly discuss mechanisms that can drive the nuclear polarization away from thermal equilibrium through mechanical rotation of samples doped with paramagnetic agents. The use of the lanthanide $\mathrm{Dy}^{3+}$ as a doping agent in either static or rotating glassy samples leads to a welcome reduction of the longitudinal relaxation times $T_{1}\left({ }^{1} \mathrm{H}\right)$ in solids. ${ }^{14,19}$ An NMR study of samples 
doped with $\mathrm{Dy}^{3+}$ spinning at low temperature should consider the possibility of a proton spin refrigerator scenario. ${ }^{20-25}$ We shall explore some properties of $\mathrm{Dy}^{3+}$ in spinning glassy samples that may have implications for DNP-MAS and possibly for 'brute force' polarization at very low sample temperatures.

\section{Proton spin refrigerator}

A crystal of yttrium ethyl sulfate doped with ytterbium,

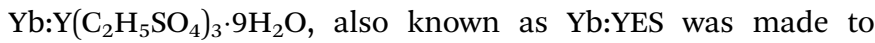
rotate around an axis perpendicular to a static magnetic field $B_{0}=1 \mathrm{~T}$ at a temperature near $1 \mathrm{~K}$ with a spinning frequency of a few tens of $\mathrm{Hz}^{20-22}$ Rotation frequencies up to a few $\mathrm{kHz}$ were reported later. ${ }^{23}$ Upon spinning the sample at $60 \mathrm{~Hz}$, the proton polarization could be boosted to $P\left({ }^{1} \mathrm{H}\right)=19 \% .{ }^{20}$ This effect could be rationalized by the interplay between the anisotropy of the electron $g$-factor, the electron relaxation time $T_{1 \mathrm{e}}$ and the proton spin relaxation time $T_{1}\left({ }^{1} \mathrm{H}\right)$. The lowest pair of energy levels in the $\mathrm{Yb}^{3+}$ EPR manifold can be described in terms of a fictitious spin $I=1 / 2$ with an anisotropic $g$-factor given by:

$$
g(\theta)=\sqrt{\left[g_{\|}^{2} \cos ^{2} \theta+g_{\perp}^{2} \sin ^{2} \theta\right]}
$$

where $g_{\|}{ }^{2}$ is parallel to the $c$ axis of the crystal while $g_{\perp}{ }^{2}$ is perpendicular to this axis, and $\theta$ is the angle subtended between the $c$ axis and the magnetic field.

\section{Static samples}

A strong intensity variation of the EPR response as a function of the angle $\theta$ was observed near $1.5 \mathrm{~K}^{24}$ At $\theta=45^{\circ}, T_{1 \mathrm{e}}$ reaches a minimum, thus allowing the electron polarization to reach the Boltzmann equilibrium in a few milliseconds. By changing the angle $\theta$ by $45^{\circ}, T_{1 \mathrm{e}}$ changes by more than two orders of magnitude and can be as long as $1 \mathrm{~s}$. At the same time, the electron splitting matches the nuclear Zeeman splitting, thus allowing cross relaxation and polarization transfer from the electron spins to the nuclear spins. ${ }^{20}$

\section{Spinning samples}

Continuous rotation leads to a periodical repetition of this process, leading to a large nuclear polarization without any need for microwave irradiation, in contrast to DNP experiments.
This process is presented in Fig. 1, and can occur in powdered samples at angles $0^{\circ}<\varphi<90^{\circ}$ where $\varphi$ is the angle between the magnetic field and the rotation axis. ${ }^{20}$ The refrigerator requires paramagnetic agents such as $\mathrm{Yb}^{3+}, \mathrm{Ce}^{3+}$ or $\mathrm{Dy}^{3+}$. The nuclear polarization is transferred by spin diffusion from protons that are close to the paramagnetic center to more distant protons..$^{20,25}$ When spinning about the magic angle, it has been demonstrated by simulations that proton spin diffusion is efficient at spinning frequencies of a few $\mathrm{kHz}$, but becomes less efficient at higher speeds. ${ }^{26}$

Variants of the concept of proton spin refrigerators were suggested based on variations of temperature, light or pressure instead of the angle $\theta$. The proton spin refrigerator can also work upon changing the magnetic field, or by inducing level crossings. $^{20}$ Different conditions on the splittings were discussed. ${ }^{25}$ Recent simulations by Thurber and Tycko demonstrated that similar effects can occur when level crossings involve three spins ${ }^{19}$ in glassy samples.

Nuclear proton polarizations as large as $P\left({ }^{1} \mathrm{H}\right)=35 \%$ at $1.3 \mathrm{~K}$ and $2 \mathrm{~T}$ could be achieved with $\mathrm{Yb}^{3+}$, with enhancements of $\varepsilon \approx 220$ with respect to thermal equilibrium under static conditions. ${ }^{23}$ Other doped crystals like Dy:YES were also shown to transfer a significant fraction of electron polarization to proton polarizations at $0.5 \mathrm{~K}$ and $0.12 \mathrm{~T}$ with a pulsed field of $0.04 \mathrm{~T}$ to polarize the electrons. ${ }^{25}$ Here, a relationship between the refrigerator cycle period and the proton polarization build up time is shown.

Right-Angle Spinning Electron Paramagnetic Resonance (RAS-EPR) involves spinning samples around an axis perpendicular with respect to the static magnetic field. ${ }^{27-29}$ This method allows one to shorten EPR acquisition times and resolve anisotropic interactions. ${ }^{27,29}$

\section{Static bleaching}

It is well known that local magnetic fields produced by paramagnetic agents may shift the nuclear resonance frequencies of nearby nuclear spins. ${ }^{3,30-32}$ This translates into line broadening and hence sensitivity losses in doped glassy static (i.e., nonspinning) samples. ${ }^{19}$ In this work, we shall refer to this effect as "static bleaching". We may define a bleaching factor $\varepsilon_{\text {bleach }}^{\text {stat }}\left({ }^{1} \mathrm{H}\right) \leq 1$ as the ratio between the areas of proton spectra of doped and

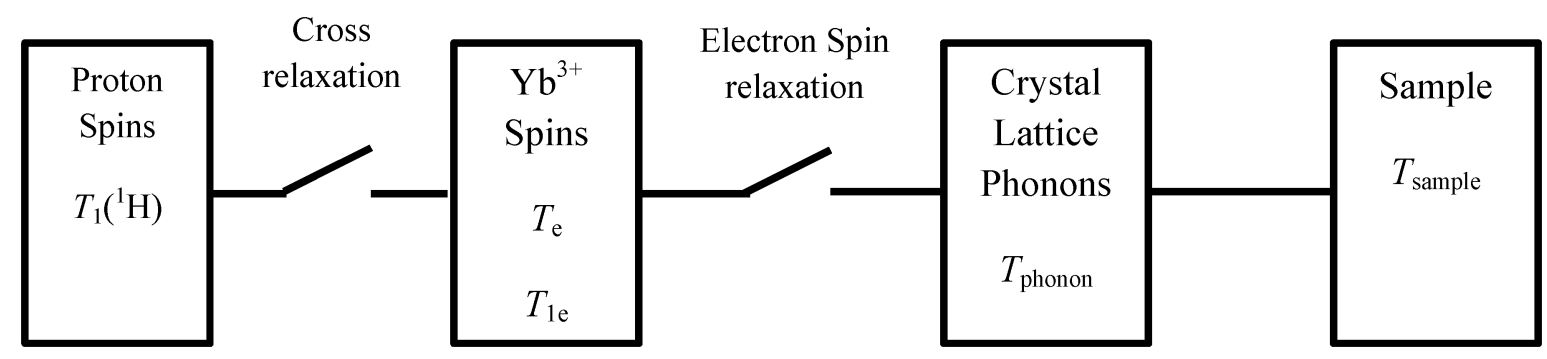

Fig. 1 Scheme showing switches involved in spin refrigerators. ${ }^{20}$ At a given orientation, the EPR splitting is maximum while the electron relaxation time $T_{1 \mathrm{e}}$ is minimum. The electron spin bath has a temperature $T_{\mathrm{e}}$ and relaxes towards thermal equilibrium while releasing heat to the phonon bath which has a

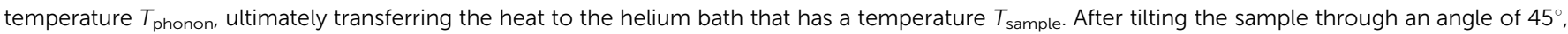
the electron splitting becomes comparable to the proton Zeeman splitting, thus favoring cross relaxation. In this step the electron bath is warmed up by the proton spin bath that is therefore cooled down. Continuous sample spinning leads to a periodic repetition of the process. 
un-doped static samples, assuming that the proton polarization has reached thermal equilibrium in both cases.

\section{Spinning-induced bleaching}

Recent observations by Thurber and Tycko in DNP-MAS studies demonstrated a significant decrease of the proton polarization $P\left({ }^{1} \mathrm{H}\right)$ with respect to thermal equilibrium in rotating glassy samples doped with paramagnetic agents as are commonly used for DNP at low temperatures. ${ }^{17,19}$ We shall refer to this effect as "spinning-induced bleaching" to distinguish it from "static bleaching". We introduce here the bleaching factor $\varepsilon_{\text {bleach }}^{\text {spin }}\left({ }^{1} \mathrm{H}\right)$ as the ratio between the area of a spectrum measured with a spinning sample and the area measured with a static sample. An extensive experimental evaluation ${ }^{18}$ at $4.9 \mathrm{~T}$ and temperatures around $80 \mathrm{~K}$ demonstrated significant losses of proton polarization $P\left({ }^{1} \mathrm{H}\right)$ in samples spinning at $\nu_{\text {rot }}=$ $4.975 \mathrm{kHz}$ with respect to non-doped samples measured indirectly with cross polarization, with $\varepsilon_{\text {bleach }}^{\text {spin }}=0.4$ when using Ox063 (Trityl) and $\varepsilon_{\text {bleach }}^{\text {spin }}=0.5$ for TOTAPOL. ${ }^{18}$

Simulations involving a system of two electron spins and one nuclear spin during MAS in the absence of microwave irradiation demonstrate the importance of the cross effect for spinning-induced bleaching: ${ }^{19,33}$ Experiments have shown that the effect decreases the area of a proton spectrum of a static sample doped with TOTAPOL or DOTOPA recorded at thermal equilibrium at $20 \mathrm{~K}$ by 5 to 6 times when spinning at $6 \mathrm{kHz}$ at the same temperature. ${ }^{19}$ The model used to explain the bleaching effect also predicted an increase of nuclear polarization $P\left({ }^{1} \mathrm{H}\right)$ under certain conditions, in particular when the nuclear Larmor frequencies are smaller than the anisotropy of the electron $g$-factor. ${ }^{19}$

\section{Increase of sample temperature due to sample rotation}

It is well known that the friction between the rotors and the flowing nitrogen gas increases the sample temperature, as can be measured using suitable NMR thermometers. ${ }^{34-37}$ To determine the DNP enhancement as a function of the spinning speed, care must be taken to monitor and control the temperature. ${ }^{38}$

Another factor that may be responsible for increasing sample temperatures has been reported in rotating samples that are doped with paramagnetic agents, especially when these paramagnetic agents exhibit large $g$-factor anisotropies like those used for spin refrigerators. This heating effect was explained by the evacuation of phonons from the proton spin bath into the sample via the electron spin bath. Non-resonant heating by relaxation depends on the concentration of paramagnetic agents and the sample temperature, among other factors. It was measured to be between 1 and $1000 \mathrm{~mW} \mathrm{~g}^{-1}$ in Yb:YES crystals when the sample was spinning about an axis perpendicular to the magnetic field. ${ }^{20,39}$

Because these effects alter the DNP enhancements, their evaluation is necessary. In this paper we shall focus on the effects of spinning of samples doped with nitroxides, lanthanides and mixtures of nitroxides and lanthanides on the longitudinal proton relaxation times $T_{1}\left({ }^{1} \mathrm{H}\right)$ and proton polarization $P\left({ }^{1} \mathrm{H}\right)$.

\section{Experimental}

The experiments were carried out using a Bruker 9.4 T spectrometer with $3.2 \mathrm{~mm}$ diameter rotors spinning at frequencies up to $12 \mathrm{kHz}$ at nominal temperatures near $100 \mathrm{~K}$. The tripleresonance probe was coupled to a gyrotron that can provide $5 \mathrm{~W}$ microwave irradiation at $263 \mathrm{GHz}$. The rotors were made of either thin-walled zirconia or sapphire. Proton saturation recovery experiments conducted in static or spinning samples used saturation by trains of 100 pulses with $90^{\circ}$ angles spaced by $1 \mathrm{~ms}$ followed by recovery intervals between 1 and $10 \mathrm{~s}$. To determine the proton build-up times $\tau_{\mathrm{DNP}}\left({ }^{1} \mathrm{H}\right), 10^{\circ}$ pulses were used. The measurements without microwave irradiation, using either un-doped samples or samples doped with lanthanides, employed $45^{\circ}$ or $90^{\circ}$ pulses. The build-up and recovery curves were fitted to mono-exponential functions to determine $\tau_{\mathrm{DNP}}\left({ }^{1} \mathrm{H}\right)$ and $T_{1}\left({ }^{1} \mathrm{H}\right)$. Cross polarization from ${ }^{1} \mathrm{H}$ to ${ }^{13} \mathrm{C}$ was performed with or without microwave irradiation. $\mathrm{DyCl}_{3}$ and $\mathrm{HoCl}_{3}$ salts were bought from Sigma Aldrich. Fresh samples were prepared less than a day before the measurements.

Three kinds of experimental data were observed in un-doped samples and in samples doped with nitroxides (TEMPOL and TOTAPOL), lanthanides $\left(\mathrm{DyCl}_{3}\right.$ and $\left.\mathrm{HoCl}_{3}\right)$ or mixtures of TEMPOL and $\mathrm{DyCl}_{3}$. The relaxation time $T_{1}\left({ }^{1} \mathrm{H}\right)$ was measured in static and spinning samples. The thermal equilibrium proton polarization $P\left({ }^{1} \mathrm{H}\right)$ was measured in static and spinning samples with a single pulse to evaluate the extent of spinninginduced bleaching. The nuclear DNP enhancement $\varepsilon_{\mathrm{DNP}}$ was measured in glycerol: $\mathrm{H}_{2} \mathrm{O} 1: 1(\mathrm{v}: \mathrm{v})$ samples doped with $50 \mathrm{mM}$ TEMPOL with or without addition of $10 \mathrm{mM} \mathrm{DyCl}_{3}$. Mixtures of different paramagnetic agents have been used for DNP at low temperatures. ${ }^{40-43}$ To evaluate the sensitivity per unit time it is necessary to account for the overall time required for the experiments. The following ratio $\kappa_{\text {spin }}$ can be defined for a doped sample:

$$
\kappa_{\text {spin }}=T_{1}\left({ }^{1} \mathrm{H}\right)^{\text {static }} / T_{1}\left({ }^{1} \mathrm{H}\right)^{\text {spinning }}
$$

To evaluate the overall enhancement it is necessary to account for the build-up time by defining the ratio $\kappa_{\mathrm{DNP}}$ :

$$
\kappa_{\mathrm{DNP}}=T_{1}^{\mathrm{un}-\operatorname{doped}}\left({ }^{1} \mathrm{H}\right) / \tau_{\mathrm{DNP}}\left({ }^{1} \mathrm{H}\right)
$$

$T_{1}^{\text {un-doped }}\left({ }^{1} \mathrm{H}\right)$ being the longitudinal relaxation time of the un-doped sample, in analogy to previous studies. ${ }^{18,44}$ Note that our factor $\kappa_{\mathrm{DNP}}$ is related to the factor $\kappa^{0}$ defined by Corzilius et $a{ }^{18}$ since $\kappa^{0}=\left(\kappa_{\mathrm{DNP}}\right)^{1 / 2}$. A factor $\varepsilon_{\text {Tot }}$ can be defined as $\varepsilon_{\text {Tot }}=\varepsilon_{\text {DNP }} \times \varepsilon_{\text {bleach }}^{\text {spin }} \times \varepsilon_{\text {bleach }}^{\text {stat }} \times\left(\kappa_{\text {DNP }}\right)^{1 / 2}$. Thus the overall effect is assumed to be given by the product of static and spinninginduced bleaching factors.

\section{Evaluation of $T_{1}\left({ }^{1} H\right)$ in samples doped with paramagnetic agents}

Longitudinal proton relaxation times $T_{1}\left({ }^{1} \mathrm{H}\right)$ were measured in static and spinning samples of glycerol: $\mathrm{H}_{2} \mathrm{O}$ doped with either $\mathrm{DyCl}_{3}$ or $\mathrm{HoCl}_{3}$. These paramagnetic agents have been used as relaxation agents in static ${ }^{14,15,19}$ and spinning ${ }^{19}$ glassy samples. 

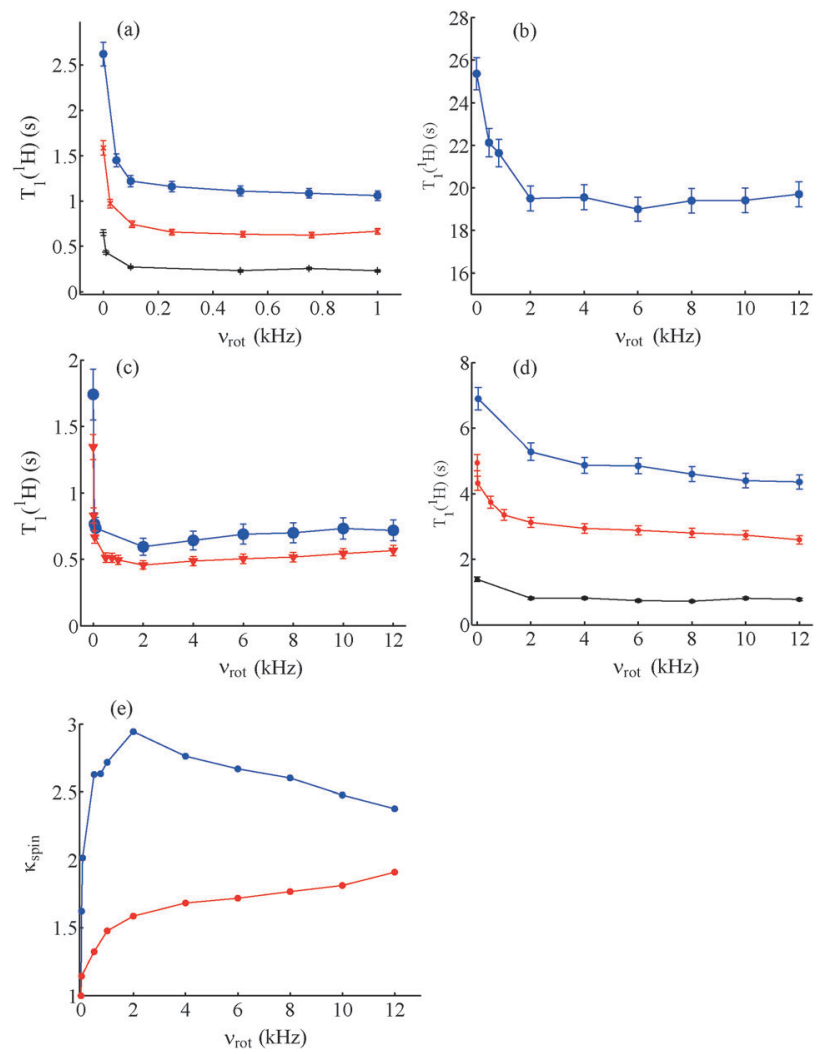

Fig. 2 (a) Relaxation times $T_{1}\left({ }^{1} \mathrm{H}\right)$ in samples of glycerol: $\mathrm{H}_{2} \mathrm{O} 60: 40(\mathrm{v}: \mathrm{v})$ doped with $10 \mathrm{mM} \mathrm{DyCl}_{3}$ (blue), $20 \mathrm{mM} \mathrm{DyCl}_{3}$ (red) and $40 \mathrm{mM} \mathrm{DyCl}_{3}$ (black) as a function of slow spinning frequencies $0<\nu_{\text {rot }}<1 \mathrm{kHz}$. (b) $T_{1}\left({ }^{1} \mathrm{H}\right)$ relaxation times in samples of un-doped glycerol: $\mathrm{H}_{2} \mathrm{O} 1: 1(\mathrm{v}: \mathrm{v})$ at spinning frequencies $0<\nu_{\text {rot }}<12 \mathrm{kHz}$. (c) Relaxation times $T_{1}\left({ }^{1} \mathrm{H}\right)$ in samples of glycerol: $\mathrm{H}_{2} \mathrm{O} 1: 1(\mathrm{v}: \mathrm{v})$ doped with $20 \mathrm{mM} \mathrm{DyCl}_{3}$ (red) and $20 \mathrm{mM} \mathrm{HoCl}_{3}$ (blue) at spinning frequencies $0<\nu_{\text {rot }}<12 \mathrm{kHz}$. (d) Relaxation times $T_{1}\left({ }^{1} \mathrm{H}\right)$ in samples of glycerol: $\mathrm{H}_{2} \mathrm{O} 1: 1(\mathrm{v}: \mathrm{v})$ doped with $25 \mathrm{mM}$ TOTAPOL (blue), $50 \mathrm{mM}$ TEMPOL (red) and a mixture of $50 \mathrm{mM}$ TEMPOL and $10 \mathrm{mM} \mathrm{DyCl}_{3}$ (black) at spinning frequencies $0<\nu_{\text {rot }}$ $<12 \mathrm{kHz}$. (e) Acceleration of the proton spin-lattice relaxation described by the factor $\kappa_{\text {spin }}=T_{1}\left({ }^{1} H\right)^{\text {static }} / T_{1}\left({ }^{1} H\right)^{\text {spinning }}$ for samples of glycerol: $\mathrm{H}_{2} \mathrm{O} 1: 1$ (v: v) doped with $20 \mathrm{mM} \mathrm{DyCl}_{3}$ (blue) and $50 \mathrm{mM}$ TEMPOL (red). All data were recorded at $9.4 \mathrm{~T}$ at a nominal temperature of $100 \mathrm{~K}$. The areas of the proton spectra were integrated after saturation recovery at thermal equilibrium for 5 samples without microwave irradiation.

Solvent mixtures with glycerol: $\mathrm{H}_{2} \mathrm{O} 60: 40(\mathrm{v}: \mathrm{v})$ or glycerol: $\mathrm{H}_{2} \mathrm{O} 50: 50$ (v:v) were used without deuteration (see Fig. 2). One does not expect a pronounced orientation dependence of $T_{1}\left({ }^{1} \mathrm{H}\right)$ in glassy static samples, unlike what has been observed in crystals. ${ }^{20}$ A strong anisotropic $g$-factor has been reported in a sample of $20 \mathrm{mM}$ Dy(III)DOTA in glycerol : $\mathrm{H}_{2} \mathrm{O} 1: 1$ (v:v). ${ }^{45}$ In samples of glycerol: $\mathrm{H}_{2} \mathrm{O}$ 60:40 (v:v) doped with different concentrations of $\mathrm{DyCl}_{3}$, slow spinning about the magic angle at $10<\nu_{\text {rot }}<100 \mathrm{~Hz}$ leads to a shortening of $T_{1}\left({ }^{1} \mathrm{H}\right)$ by nearly a factor of two compared to static samples (Fig. 2). A decrease of $T_{1}\left({ }^{1} \mathrm{H}\right)$ with an increase in the lanthanide concentration can also be observed in static samples in Fig. $2 \mathrm{a} .{ }^{14} \mathrm{~A}$ less dramatic shortening of $T_{1}\left({ }^{1} \mathrm{H}\right)$ was observed with an increase in the spinning frequency $\nu_{\text {rot }}$ in an un-doped sample of glycerol $: \mathrm{H}_{2} \mathrm{O}$ $1: 1(\mathrm{v}: \mathrm{v})$ (Fig. 2b), showing a minimum near $\nu_{\mathrm{rot}}=2 \mathrm{kHz}$.
The appearance of such a minimum was common to all glassy samples studied in this work, as shown in Fig. 2. However, the reduction of $T_{1}\left({ }^{1} \mathrm{H}\right)$ was not as pronounced as for lanthanides. Fig. 2c shows a comparison of $T_{1}\left({ }^{1} \mathrm{H}\right)$ measured in static and spinning samples of glycerol: $\mathrm{H}_{2} \mathrm{O} 1: 1(\mathrm{v}: \mathrm{v})$ doped with $20 \mathrm{mM}$ $\mathrm{DyCl}_{3}$ and $20 \mathrm{mM} \mathrm{HoCl}$. In Fig. 2(a) and (c), $T_{1}\left({ }^{1} \mathrm{H}\right)$ first drops sharply near $\nu_{\text {rot }}=100 \mathrm{~Hz}$ and then continues to decrease slowly to a minimum near $\nu_{\text {rot }}=2 \mathrm{kHz}$. The shortening of $T_{1}\left({ }^{1} \mathrm{H}\right)$ with an increase in $\nu_{\text {rot }}$ in the absence of paramagnetic agents, shown in Fig. 2b, can be ascribed to the acceleration of spin diffusion with an increase of $\nu_{\text {rot }}{ }^{26}$ Small amounts of paramagnetic molecular oxygen may also play a role. For spinning frequencies $\nu_{\text {rot }}>2 \mathrm{kHz}, T_{1}\left({ }^{1} \mathrm{H}\right)$ tends to increase slightly, as in Fig. 2c. Indeed, high spinning frequencies $\nu_{\text {rot }}$ lead to inefficient spin diffusion. $^{26}$

Fig. $2 \mathrm{~d}$ shows $T_{1}\left({ }^{1} \mathrm{H}\right)$ as a function of the spinning frequency $\nu_{\text {rot }}$ for samples of glycerol: $\mathrm{H}_{2} \mathrm{O} 1: 1(\mathrm{v}: \mathrm{v})$ doped with $50 \mathrm{mM}$ TEMPOL, $25 \mathrm{mM}$ TOTAPOL, $50 \mathrm{mM}$ TEMPOL and $10 \mathrm{mM}$ $\mathrm{DyCl}_{3}$. Although there is an initial decrease in $T_{1}\left({ }^{1} \mathrm{H}\right)$ for samples doped only with nitroxides, this decrease amounts to merely $10 \%$ of $T_{1}\left({ }^{1} \mathrm{H}\right)$ at $\nu_{\text {rot }}=100 \mathrm{~Hz}$, similar to un-doped samples.

Fig. 2e shows $\kappa_{\text {spin }}$ for samples of glycerol: $\mathrm{H}_{2} \mathrm{O} 1: 1(\mathrm{v}: \mathrm{v})$ doped either with $50 \mathrm{mM}$ TEMPOL or $20 \mathrm{mM} \mathrm{DyCl}_{3}$. The trend in samples doped with $\mathrm{Dy}^{3+}$ is for $\kappa_{\text {spin }}$ to increase sharply until $\nu_{\text {rot }}=2 \mathrm{kHz}$ and then to decrease, whereas for samples doped with TEMPOL there is little effect until $\nu_{\text {rot }}=2 \mathrm{kHz}$ followed by an increase at higher spinning frequencies.

Bleaching in static samples was evaluated by proton saturation recovery experiments at $9.4 \mathrm{~T}$ and $100 \mathrm{~K}$ for glycerol $: \mathrm{H}_{2} \mathrm{O}$ $1: 1(\mathrm{v}: \mathrm{v})$ doped with $50 \mathrm{mM}$ TEMPOL with or without $10 \mathrm{mM}$ $\mathrm{DyCl}_{3}$. The static bleaching factors were $\varepsilon_{\text {bleach }}^{\text {stat }}=0.83$ and 0.89 for samples doped with TEMPOL with and without $\mathrm{DyCl}_{3}$ respectively. In the un-doped sample, $\varepsilon_{\text {bleach }}^{\text {stat }}=1$ (Fig. 3a). Considering a model of effective bleached spheres, where each paramagnetic agent influences a spherical volume with a radius $r$, we determined that $r<10 \AA$ for TEMPOL and $r<13 \AA$ for $\mathrm{DyCl}_{3}$. Our estimates did not take line broadening into account, in agreement with ref. 33. Measurements on samples that are un-doped or doped with $\mathrm{DyCl}_{3}$ only showed smaller bleached spheres, with an effective $r=9 \AA$ (data not shown). An effective bleached sphere for $\mathrm{Yb}^{3+}$ with $r=7 \AA$ was suggested in Yb:YES. ${ }^{20}$ In any case the existence of paramagnetic impurities in glassy matrices leads to small sensitivity losses. ${ }^{18,46}$ On the other hand the presence of paramagnetic agents leads to a shortening of $T_{1}\left({ }^{1} \mathrm{H}\right)$, which may boost the sensitivity per unit time.

Bleaching in spinning samples was determined by comparing the areas of the proton spectra of static and spinning samples at thermal equilibrium. A thin-walled zirconia rotor was used for these measurements. The spectra of static samples and samples spinning at $\nu_{\text {rot }}=12 \mathrm{kHz}$ recorded using un-doped samples of glycerol: $\mathrm{H}_{2} \mathrm{O} 1: 1(\mathrm{v}: \mathrm{v})$ and samples doped with either $50 \mathrm{mM}$ TEMPOL alone or with $50 \mathrm{mM}$ TEMPOL plus $10 \mathrm{mM} \mathrm{DyCl}_{3}$ are shown in Fig. 3. A $20 \%$ decrease of the signal area occurs when spinning the sample doped only with $50 \mathrm{mM}$ TEMPOL at $\nu_{\text {rot }}=12 \mathrm{kHz}$ (Fig. 3c) compared to the static 
(a)

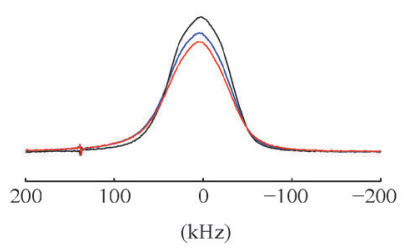

(c)

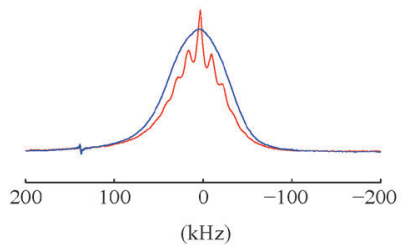

(e)

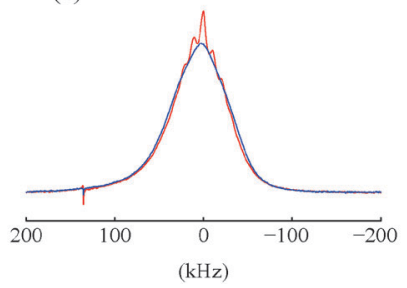

Fig. 3 (a) Proton spectra at thermal equilibrium of a static un-doped sample of glycerol: $\mathrm{H}_{2} \mathrm{O} 1: 1$ (v:v) (black), of a similar sample doped with $50 \mathrm{mM}$ TEMPOL (blue) and of a similar sample doped with $50 \mathrm{mM}$ TEMPOL and $10 \mathrm{mM} \mathrm{DyCl}_{3}$ (red). (b) Proton spectra of a static un-doped sample of glycerol: $\mathrm{H}_{2} \mathrm{O} 1: 1(\mathrm{v}: \mathrm{v})$ (blue) and of the same sample spinning at $12 \mathrm{kHz}$ (red). (c) Proton spectra of a static sample of glycerol: $\mathrm{H}_{2} \mathrm{O}$ doped with $50 \mathrm{mM}$ TEMPOL (blue) and of the same sample spinning at $12 \mathrm{kHz}$ (red). (d) Proton spectra of a static sample of glycerol: $\mathrm{H}_{2} \mathrm{O}$ doped with $50 \mathrm{mM}$ TEMPOL and $10 \mathrm{mM} \mathrm{DyCl}_{3}$ (blue) and of the same sample spinning at $12 \mathrm{kHz}$ (red). (e) Proton spectra of a static sample of glycerol : $\mathrm{H}_{2} \mathrm{O}$ doped with $10 \mathrm{mM} \mathrm{DyCl}_{3}$ (blue) and of the same sample spinning at $12 \mathrm{kHz}$ (red). All data were taken at $9.4 \mathrm{~T}$ at a nominal temperature of $100 \mathrm{~K}$.

sample. Although significant, this decrease is not as important as was found at lower temperatures. ${ }^{18,19}$ Adding $10 \mathrm{mM} \mathrm{DyCl}_{3}$ enhances static bleaching as shown in Fig. 3a, but reduces spinning-induced bleaching in comparison with samples doped with TEMPOL only. In the case of un-doped samples (Fig. 3b), the areas of the proton spectra show a small decrease at $\nu_{\text {rot }}=12 \mathrm{kHz}$ compared to the static spectra. In this sample the spinning-induced bleaching is not as significant as in samples doped only with nitroxides (Fig. 3c). Another example in Fig. 3e shows two proton spectra of glycerol: $\mathrm{H}_{2} \mathrm{O} 1: 1(\mathrm{v}: \mathrm{v})$ doped with $20 \mathrm{mM} \mathrm{DyCl}_{3}$ at thermal equilibrium and $\nu_{\text {rot }}=0$ or $10 \mathrm{kHz}$. The lack of spinning-induced bleaching is clearly seen. Samples doped with $20 \mathrm{mM} \mathrm{HoCl}$ did not show any significant bleaching.

The behavior of bleaching at different spinning frequencies can be seen in Fig. 4a. In samples doped with nitroxides, spinning-induced bleaching reduces the area of the proton spectra when the spinning speed is increased. For a sample of glycerol: $\mathrm{H}_{2} \mathrm{O} 1: 1(\mathrm{v}: \mathrm{v})$ with $50 \mathrm{mM}$ TEMPOL, the bleaching
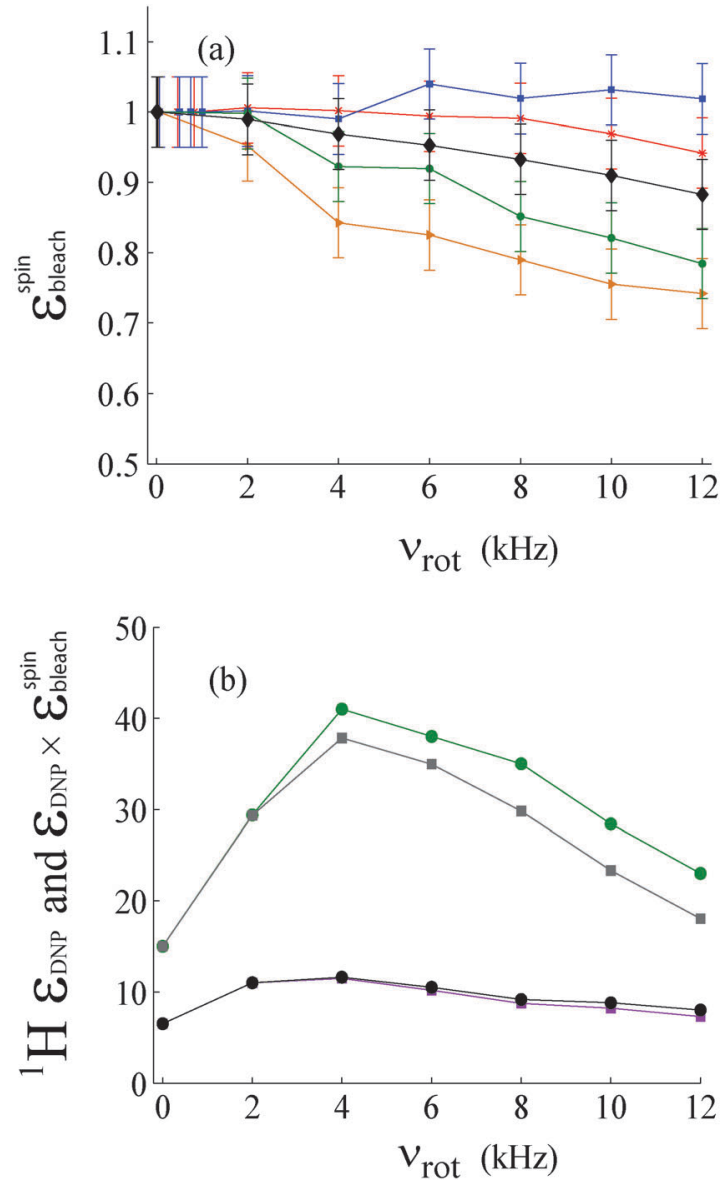

Fig. 4 (a) Bleaching factor $\varepsilon_{\text {bleach }}^{\text {spin }}$ due to spinning measured for five samples of glycerol: $\mathrm{H}_{2} \mathrm{O}$ 1:1 ( $\mathrm{v}: \mathrm{v}$ ) doped with $20 \mathrm{mM} \mathrm{DyCl}_{3}$ (blue), $50 \mathrm{mM}$ TEMPOL (green), $25 \mathrm{mM}$ TOTAPOL (orange), a mixture of $50 \mathrm{mM}$ TEMPOL and $10 \mathrm{mM} \mathrm{DyCl}$ (black) and without any doping (red). (b) DNP proton polarization enhancements measured in two samples of glycerol: $\mathrm{H}_{2} \mathrm{O}$ 1:1 ( $\mathrm{v}: \mathrm{v}$ ) doped with $50 \mathrm{mM}$ TEMPOL (green), after correction for bleaching due to spinning (grey), for a mixture of $50 \mathrm{mM}$ TEMPOL and $10 \mathrm{mM} \mathrm{DyCl}_{3}$ (black) and after correction for bleaching due to spinning (purple). All data were taken at $9.4 \mathrm{~T}$ and a nominal temperature of $100 \mathrm{~K}$. The lines are drawn to guide the eye.

factor is $\varepsilon_{\text {bleach }}^{\text {spin }}=0.8$ for $\nu_{\text {rot }}=12 \mathrm{kHz}$ (see also Fig. 3c). By adding $10 \mathrm{mM} \mathrm{DyCl}_{3}, \varepsilon_{\text {bleach }}^{\text {spin }}$ increases to 0.9 at $\nu_{\text {rot }}=12 \mathrm{kHz}$ (Fig. 3d). It is known that the presence of $\mathrm{DyCl}_{3}$ combined with TEMPOL may shorten the latter's longitudinal electron relaxation time $T_{1 \mathrm{e}}{ }^{40-42,45}$ In samples doped with both agents, spinning-induced bleaching is reduced. The factor is $\varepsilon_{\text {bleach }}^{\text {stat }} \approx 1$ for $1: 1$ glycerol: $\mathrm{H}_{2} \mathrm{O}(\mathrm{v}: \mathrm{v})$ doped with $20 \mathrm{mM} \mathrm{DyCl}_{3}$. If we disregard the measurement at $12 \mathrm{kHz}$, it is also the same for the un-doped sample.

A sample of 1:1 glycerol: $\mathrm{H}_{2} \mathrm{O}(\mathrm{v}: \mathrm{v})$ doped with $25 \mathrm{mM}$ TOTAPOL showed a more pronounced spinning-induced bleaching, since $\varepsilon_{\mathrm{bleach}}^{\mathrm{spin}}=0.74$ at $12 \mathrm{kHz}$. This is consistent with the more effective cross effect in biradicals, as shown by simulations. ${ }^{19}$

Samples doped with nitroxides tend to show a decrease in the signal intensity when the spinning speed is increased. The intensity decreases almost linearly with an increase in the 
spinning frequency at $100 \mathrm{~K}$ and $9.4 \mathrm{~T}$. It is shown in Fig. 3 and 4 that this effect is not as pronounced as that observed near $20 \mathrm{~K}$, with $\varepsilon_{\text {bleach }}^{\text {spin }}=0.1$ to $0.2 .^{19}$

Dynamic nuclear polarization enhancements were measured in a sample of glycerol: $\mathrm{H}_{2} \mathrm{O}$ 1:1 (v:v) doped with $50 \mathrm{mM}$ TEMPOL. $T_{1}\left({ }^{1} \mathrm{H}\right)$ and build-up times $\tau_{\text {DNP }}\left({ }^{1} \mathrm{H}\right)$ were measured by saturation recovery. Enhancements were measured by cross polarization from ${ }^{1} \mathrm{H}$ to ${ }^{13} \mathrm{C}$, using rf fields of $125 \mathrm{kHz}$ for ${ }^{1} \mathrm{H}$ during the $90^{\circ}$ pulse and $78 \mathrm{kHz}$ during the contact time. Spinal-64 proton decoupling was used with an $\mathrm{rf}$ field of $78 \mathrm{kHz}$. Proton DNP build-up times were measured to be $\tau_{\mathrm{DNP}}\left({ }^{1} \mathrm{H}\right)=2.5 \pm 0.2 \mathrm{~s}$ for the sample with $50 \mathrm{mM}$ TEMPOL and $\tau_{\mathrm{DNP}}\left({ }^{1} \mathrm{H}\right)=0.55 \pm 0.2 \mathrm{~s}$ for a sample with $50 \mathrm{mM}$ TEMPOL plus $10 \mathrm{mM} \mathrm{DyCl}_{3}$ for $2<\nu_{\text {rot }}<12 \mathrm{kHz}$. An increased enhancement was observed with an increase in the spinning speed until a maximum around $\nu_{\text {rot }}=4 \mathrm{kHz}$. Beyond this point the enhancement decreases as shown experimentally and explained theoretically. ${ }^{48,49}$

A straightforward correction of the proton enhancement is shown in Fig. 4b for both samples by multiplying the enhancement by their respective values of $\varepsilon_{\text {bleach }}^{\text {spin }}$. In the case of the sample doped with TEMPOL only, there is an overall loss of about $20 \%$ when spinning at $12 \mathrm{kHz}$. The reduction of the enhancement with an increase in the spinning frequency is more pronounced than for the case of the doubly-doped sample containing both TEMPOL and $\mathrm{DyCl}_{3}$ where the enhancement was less than in the sample containing only TEMPOL as the doping agent, presumably because of a leakage of polarization.,47

According to data in Fig. 2-4 for samples doped with TEMPOL with or without $\mathrm{DyCl}_{3}$ at $\nu_{\text {rot }}=4 \mathrm{kHz}$, the factors are $\varepsilon_{\text {TOT }}=55$ and 92, respectively. The factors $\varepsilon_{\text {TOT }}$ are 37 and 45 at $\nu_{\text {rot }}=12 \mathrm{kHz}$ for samples with or without $\mathrm{DyCl}_{3}$, respectively. This suggests that $\mathrm{DyCl}_{3}$ could be used to enhance DNP at higher spinning speeds, albeit at the expense of slightly greater linewidths.

\section{Discussion}

The marked reduction of $T_{1}\left({ }^{1} \mathrm{H}\right)$ in samples doped with lanthanides such as $\mathrm{Dy}^{3+}$ or $\mathrm{Ho}^{3+}$ at spinning frequencies as low as $\nu_{\text {rot }}$ $=0.1 \mathrm{kHz}$ and in the absence of spinning-induced bleaching is consistent with the principles of the proton spin refrigerator discussed above for lanthanides such as $\mathrm{Yb}^{3+}, \mathrm{Ce}^{3+}$ (ref. 20) or $\mathrm{Dy}^{3+}$ (ref. 25) and also at low sample spinning frequencies. These principles are also valid for powdered samples that are spinning about angles that are not orthogonal to the static field. $^{20,23}$ Simulations by Thurber and Tycko confirm the possibility of effects similar to those of spin refrigerators in MAS-NMR of glassy samples, ${ }^{19}$ but other lanthanides like Dy ${ }^{3+}$ were not specifically addressed.

A reduction of $T_{1}\left({ }^{1} \mathrm{H}\right)$ was observed in all samples, with a minimum near $\nu_{\text {rot }}=2 \mathrm{kHz}$. This feature is consistent with the common observation that proton spin diffusion is facilitated at low spinning frequencies, as confirmed by simulations. ${ }^{26}$ However, the reduction of $T_{1}\left({ }^{1} \mathrm{H}\right)$ at low spinning frequencies is not as pronounced when using TEMPOL or TOTAPOL only rather than lanthanides, which lead to a minimum at frequencies as low as $\nu_{\text {rot }}=0.1 \mathrm{kHz}$.

Despite the sharp reduction of $T_{1}\left({ }^{1} \mathrm{H}\right)$ when the sample is spinning at a few tens of $\mathrm{Hz}$, the experimental conditions for the proton spin refrigerator to increase the proton polarization are not completely fulfilled, since the rotor period is not short in comparison with $T_{1 \mathrm{e}}$. For $\mathrm{Dy}^{3+}$ at $100 \mathrm{~K}, T_{1 \mathrm{e}}$ is expected to be much shorter than the rotor period $\tau_{\text {rot }}=83.3 \mu$ s when spinning at $\nu_{\text {rot }}=12 \mathrm{kHz}$. A discussion about different Zeeman splittings, along with a relationship between $T_{1}\left({ }^{1} \mathrm{H}\right)$ and the rotor period is provided. ${ }^{25}$ Data for samples of water and glycerol $1: 1(\mathrm{v}: \mathrm{v})$ doped with $20 \mathrm{mM} \mathrm{DyCl}{ }_{3}$ showed a clear absence of bleaching due to spinning at $\nu_{\text {rot }}=10$ or $12 \mathrm{kHz}$, whereas for un-doped samples a small signal reduction was observed. No bleaching due to spinning was expected for either of these samples.

The reduction of $T_{1}\left({ }^{1} \mathrm{H}\right)$ observed in glassy samples doped with lanthanides when spinning at low frequencies may provide an alternative strategy for nuclear polarization relaxation experiments at much lower temperatures, as used for "brute force polarization" in glassy samples doped with paramagnetic agents. This could be exploited by either spinning of the sample or the magnetic field. ${ }^{20,23}$

The fact that the NMR signal area decreases in samples doped with nitroxides like TEMPOL or TOTAPOL has been explained qualitatively. Simulations show that the interactions between two electron spins and one nuclear spin that can lead to the so-called 'cross effect' can be responsible not only for DNP enhancements but also for signal losses. ${ }^{19,48-50}$ However, the decrease of the NMR response may involve mechanisms other than the cross effect, since a homogeneous saturation of the EPR response (as occurs when increasing the temperature) may be equivalent to irradiation near the center of gravity of the EPR response, thus producing simultaneous zero- and doublequantum transitions, leading to a nuclear polarization that is smaller than that at thermal equilibrium. RAS-EPR could play an important role in determining contributions of different mechanisms to the perturbation of the nuclear magnetic polarization in samples doped with paramagnetic agents that are subject to rotation. In this work we used high concentrations of paramagnetic nitroxides (either TOTAPOL or TEMPOL) to observe spinning-induced bleaching. The use of crosspolarization to evaluate the bleaching effect provides an indirect way to determine the losses of proton polarization. ${ }^{18,19}$ However, the efficiency of cross polarization may vary from sample to sample and may cause further losses that are not necessarily due to bleaching induced by spinning.

\section{Conclusions}

We have evaluated proton NMR signal intensities and longitudinal proton relaxation times $T_{1}\left({ }^{1} \mathrm{H}\right)$ of glassy samples doped with paramagnetic agents spinning at the magic angle near $100 \mathrm{~K}$ at $9.4 \mathrm{~T}$. The bleaching of the proton polarization due to spinning at $12 \mathrm{kHz}$ leads to a loss of $25 \%$ in samples doped 
with 25 mM TOTAPOL and a loss of $20 \%$ in samples doped with $50 \mathrm{mM}$ TEMPOL. These polarization losses are less severe than those measured by Corzilius et al., ${ }^{18}$ in agreement with predictions of Thurber and Tycko ${ }^{19}$ that the bleaching effect should be less severe at higher temperatures and lower concentrations of paramagnetic agents. ${ }^{18}$ By adding $\mathrm{DyCl}_{3}$ to samples doped with nitroxide radicals it was possible to reduce spinninginduced bleaching, at the expense of some static bleaching and some line broadening. This strategy could be useful at higher spinning speeds and lower temperatures. At relatively high concentrations of nitroxides, we observe a significant decrease of the proton polarization at spinning speeds near $12 \mathrm{kHz}$, with an almost linear dependence on the spinning frequency. Compared to static samples, a significant reduction of $T_{1}\left({ }^{1} \mathrm{H}\right)$ has been observed in glassy samples doped with $\mathrm{Dy}^{3+}$ and $\mathrm{Ho}^{3+}$ spinning at frequencies as low as $0.1 \mathrm{kHz}$. The reduction of $T_{1}\left({ }^{1} \mathrm{H}\right)$ in these glassy samples, which is reminiscent of proton spin refrigerators that use similar paramagnetic agents in crystalline samples, ${ }^{25}$ allows one to decrease the recovery delays between subsequent experiments and hence obtain a better signal-to-noise ratio per unit time.

\section{Acknowledgements}

AJPL would like to thank Professor T. Wenckebach for constructive conversations. This work was supported by the Swiss National Science Foundation (SNSF), the Ecole Polytechnique Fédérale de Lausanne (EPFL), the Swiss Commission for Technology and Innovation (CTI), Bruker Biospin, the French CNRS, and the European Research Council (ERC Advanced Grant 339754 “Dilute Para-Water”).

\section{References}

1 A. Overhauser, Phys. Rev., 1953, 92, 411.

2 T. R. Carver and C. P. Slichter, Phys. Rev., 1953, 92, 212.

3 A. Abragam and M. Goldman, Rep. Prog. Phys., 1978, 41, 395.

4 K. N. Hu, G. T. Debelouchina, A. A. Smith and R. Griffin, J. Chem. Phys., 2011, 134, 125105.

5 T. Maly, G. T. Debelouchina, V. S. Bajaj, K. N. Hu, C. G. Joo, M. L. Mak-Jurkauskas, J. R. Sirigiri, P. C. A. van der Wel, J. Herzfeld, R. J. Temkin and R. G. Griffin, J. Chem. Phys., 2008, 128, 052211.

6 C. Song, K. N. Hu, C.-G. Joo, T. Swager and R. G. Griffin, J. Am. Chem. Soc., 2006, 128, 11385.

7 W. Th. Wenckebach, T. J. B. Swanenburg and N. J. Poulis, Phys. Rep., 1974, 14, 181.

8 B. N. Provotorov, Sov. Phys. JETP, 1962, 14, 1126.

9 V. A. Atsarkin, Usp. Fiz. Nauk, 1978, 126, 3.

10 C. D. Jeffries, Annu. Rev. Nucl. Sci., 1964, 14, 101.

11 T. Prisner and W. Kockenberger, Appl. Magn. Reson., 2008, 34, 213.

12 R. G. Griffin and T. F. Prisner, Phys. Chem. Chem. Phys., 2010, 12, 5737.
13 J. H. Ardenkjaer-Larsen, B. Fridlund, A. Gram, G. Hansson, M. Lerche, R. Servin, M. Thaning and K. Golman, Proc. Natl. Acad. Sci. U. S. A., 2003, 100, 10158.

14 D. G. Gadian, K. S. Panesar, A. J. Perez Linde, A. J. Horserwill, W. Köckenberger and J. R. Owers-Bradley, Phys. Chem. Chem. Phys., 2012, 14, 5397.

15 D. T. Peat, A. J. Horsewill, W. Köckenberger, A. J. Perez Linde, D. G. Gadian and J. R. Owers-Bradley, Phys. Chem. Chem. Phys., 2013, 15, 758.

16 J. Owers Bradley, A. J. Horsewill, D. T. Peat, K. S. H. Goh and D. Gadian, Phys. Chem. Chem. Phys., 2013, 15, 10413.

17 R. Tycko, 18th ISMAR Meeting, Rio de Janeiro, May 2013.

18 B. Corzilius, L. B. Andreas, A. A. Smith and Q. Z. Ni. R. Griffin, J. Magn. Reson., 2014, 240, 113.

19 K. Thurber and R. Tycko, J. Phys. Chem., 2014, 140, 184201. 20 K. H. Langley and C. D. Jeffries, Phys. Rev., 1966, 152, 358. 21 C. D. Jeffries, Cryogenics, 1963, 3, 41.

22 A. Abragam, Cryogenics, 1963, 3, 42.

23 J. R. McColl and C. D. Jeffries, Phys. Rev. Lett., 1966, 16, 8. 24 J. P. Wolfe and D. C Jeffries, Phys. Rev., 1971, 4, 3.

25 H. B. Brom and W. J. Huiskamp, Physica, 1972, 60, 1631973, 66, 43.

26 M. E. Halse, J.-N. Dumez and L. Emsley, J. Chem. Phys., 2012, 136, 224511.

27 G. A. Sierra and A. Schweiger, Rev. Sci. Instrum., 1997, 68(2), 1326.

28 G. A. Sierra, M. A. Schuler and A. Schweiger, Chem. Phys. Lett., 1999, 303, 475.

29 D. Hessinger, C. Bauer, G. Jeschke and H. W. Spiess, Appl. Magn. Reson., 2001, 20, 17.

30 N. Bloembergen, Physica, 1949, 3, 4.

31 W. E. Blumberg, Phys. Rev., 1960, 119, 1.

32 S. Lange, A. H. Linden, Ü. Akbey, W. T. Franks, N. Loening, B.-J. Van Rossum and H. Oschkinat, J. Magn. Reson., 2012, 216, 209.

33 F. Mentink-Vigier, COST Meeting near Southampton, 2014, private communication.

34 R. N. Purusottam, G. Bodenhausen and P. Tekely, J. Magn. Reson., 2014, 246, 69.

35 K. R. Thurber and R. Tycko, J. Magn. Reson., 2009, 196, 84.

36 P. Miéville, V. Vitzthum, M. A. Caporini, S. Jannin, S. Gerber-Lemaire and G. Bodenhausen, Magn. Reson. Chem., 2011, 49, 689.

37 M. Rosay, L. Tometich, S. Pawsey, R. Bader, R. Schauwecker, M. Blank, P. M. Borchard, S. R. Cauffman, K. L. Felch, R. T. Weber, R. J. Temkin, R. G. Griffin and W. E. Maas, Phys. Chem. Chem. Phys., 2010, 12, 5850.

38 A. Zagdoun, G. Casano, O. Ouari, M. Schwarzwälder, A. J. Rossini, F. Aussenac, M. Yulikov, G. Jeschke, C. Copéret, P. Tordo and L. Emsley, J. Am. Chem. Soc., 2013, 135, 12790.

39 W. J. Potter and H. J. Stapleton, Phys. Rev. B: Condens. Matter Mater. Phys., 1972, 5, 1729.

40 J. H. Ardenkjaer Larsen, S. Macholl and H. Johannesson, Appl. Magn. Reson., 2008, 34, 509. 
41 J. W. Gordon, S. B. Fain and I. J. Rowland, Magn. Reson. Med., 2012, 68, 4949.

42 H. Johannesson, S. Macholl and J. H. Ardenkjaer-Larsen, J. Magn. Reson., 2009, 197, 167.

43 V. K. Michaelis, A. A. Smith, B. Corzilius, O. Haze, T. M. Swager and R. G. Griffin, J. Am. Chem. Soc., 2013, 135, 2935.

44 T. Kobayashi, O. Lafon, A. S. Lilly Thankamony, I. I. Slowing, K. Kandel, D. Carnevale, V. Vitzthum, H. Vezin, J.-P. Amoureux, G. Bodenhausen and M. Pruski, Phys. Chem. Chem. Phys., 2013, 15, 5553.

45 P. Lueders, S. Razzaghi, H. Jäger, R. Tschaggelar, M. A. Hemminga, M. Yulikov and G. Jeschke, Mol. Phys., 2013, 111, 2824.
46 A. J. Rossini, A. Zagdoun, M. Lelli, D. Gajan, F. Rascon, M. Rosay, W. E. Maas, C. Copéret, A. Lesage and L. Emsley, Chem. Sci., 2012, 3, 108.

47 O. Lafon, A. S. L. Thankamony, M. Rosay, F. Aussenac, X. Lu, J. Trébosc, V. Bout-Roumazeilles and J. P. Amoureux, Chem. Commun., 2013, 49, 2864.

48 K. Thurber and R. Tycko, J. Chem. Phys., 2012, 137, 084508.

49 F. Mentink-Vigier, Ü. Akbey, Y. Hovav, S. Vega and H. Oschkinat, J. Magn. Reson., 2012, 224, 13.

50 A. N. Pravdivtsev, A. V. Yurkovskaya, R. Kaptein, K. Miesel, H. M. Vieth and K. L. Ivanov, Phys. Chem. Chem. Phys., 2013, 15, 14660 . 